\title{
Using Interactive Technology to Develop Preservice Teachers' STEAM Competencies in Early Childhood Education Program
}

\author{
Areej ElSayary ${ }^{1^{*}} \mathbb{D}$, Rana Zein ${ }^{1}$ (D) , Lani San Antonio ${ }^{1}$ (D) \\ ${ }^{1}$ Education Studies, Zayed University, Abu Dhabi, UNITED ARAB EMIRATES \\ Received 30 November 2021 - Accepted 20 January 2022
}

\begin{abstract}
Using interactive technology leads to an interactive learning environment where learners develop their STEAM competencies, including critical thinking, collaboration, communication, creativity and innovation, self-direction, connection, and the use of interactive technology tools effectively. This research aims to investigate the use of interactive technology in developing preservice teachers' STEAM competencies. The participants were preservice teachers $(n=80)$ in an early childhood education program at a Federal University in the United Arab Emirates. An explanatory sequential mixed-method approach used quantitative analysis (quasi-experiment) followed by a qualitative approach (a focus group discussion was conducted). An online survey was used to collect the quantitative data from the participants before the semester started. It was sent again to participants at the end of the semester. The focus group discussions were used to collect the data from selected participants from the experimental group $(n=18)$. The study results reveal a significant positive impact on the development of preservice teachers' STEAM competencies after using the interactive technology.
\end{abstract}

Keywords: interactive technology, STEAM competencies, interactive learning

\section{INTRODUCTION}

The reform of the educational system in the United Arab Emirates (UAE) is one of the country's national agenda goals (UAE Vision, 2009, 2021). There is a significant shift from the dependence on oil toward a knowledge-based economy in the Gulf region. Accordingly, the UAE's 2030 agenda for sustainable development stated goals and objectives toward a new transformation in education. These goals included preparing students for jobs that do not yet exist by reforming the curricula to focus on $21^{\text {st-century skills }}$ where learning is empowered by technology (UAE National Committee, 2017). Enabling learners to acquire the skills needed to be successful citizens is one of the main aims and purposes of Science, Technology, and Innovation Policy (STI) (UAE Government, 2015). In the World Education Forum (WEF) report, a survey investigating the workforce skills of a group of companies showed that UAE workforce skills were rated as average $(71.7 \%)$ in $2019-2020$. The skills were active learning and learning strategies, leadership, and social influence, analytical thinking and innovation, quality control and safety awareness, complex problem-solving, critical thinking and analysis, management of personnel, creativity, originality and initiative, technology use, monitoring and control, and service orientation (Schwab \& Zahidi, 2020). Therefore, there is still a need to improve the UAE's workforce skills in general and specifically in the education sector.

Science, technology, engineering, and mathematics (STEM) education is a unique approach to teaching and learning in early childhood education that focuses on a student-centered approach. STEM refers to integrating scientific subjects, while STEAM refers to integrating scientific and non-scientific subjects where arts (nonscientific subjects) is added to the STEM (scientific subjects). In the STEAM framework created by Yakman (2010), defined the art to be language arts, history, sociology, psychology, design art, and performance arts. The novelty in each of the fields is as follows: science novelty is in hands-on learning, technology is in the projects, engineering is in the design planning, while art is in the innovative products, and mathematics is in the 


\section{Contribution to the literature}

- This study investigated the use of interactive technology in developing preservice teachers' STEAM competencies.

- The study highlights how the interactive technology helps preservice teachers to develop interactive lessons for early years' students.

- The study proposes suggestions for future research about the impact of these changes on the education system.

prominent use of modeling (Drake \& Reid, 2017). The rapid development of science and technology has changed the demands of teachers' competencies. Using interactive technology is important for developing teachers' STEAM competencies essential for the interdisciplinary teaching of science, technology, engineering, and mathematics (STEM) (Chai et al., 2020).

\section{Conceptual Framework}

The technological pedagogical content knowledge (TPCK) framework is a conceptual framework used by researchers and educators to provide the fundamental knowledge teachers need as they construct technologyintegrated lesson plans (Mohebi, 2018). It is evident that using technology to plan lessons is a reliable pedagogical approach that enhances teachers' competencies (Chai et al., 2020). The pedagogical content knowledge (PCK) conceived by Shulman in 1986, defines the pedagogical aspects, and specific contents of the discipline (Capone \& Lepore, 2021). Pierson (1999) clarified the TPCK framework as the integration of the three domains of knowledge: technology, pedagogy, and content of the discipline. Gess-Newsom (1999) presented two different models: the integrative model and transformative model. The integrative model is the merging of three separate domains (content, pedagogy, and technology) during the teaching and learning process. The transformative model is the integration of the three domains (content, pedagogy, and technology) in a holistic way to support educators in the teaching and learning process (Capone \& Lepore, 2021). This study uses a conceptual framework that incorporates the subskills included in each of the three domains of knowledge. Critical thinking and connection are considered as sub-skills inherent in the content knowledge domain. The use of interactive technology applications, creativity and innovation are considered as sub-skills inherent in the technology knowledge domain. Finally, the collaboration, communication, and selfdirection are sub-skills that are inherent in the pedagogy knowledge domain. ElSayary (2014) states that the most important challenge in the transformation of teaching practices is to provide an interactive learning environment, that supports the development of students' higher-order thinking skills. The interactive technology tool helps educators to promote students' skills through creating an interactive learning environment.

\section{Competencies and Interactive Technology}

In the last two decades there has been particular attention to the term "competency" in the field of education (Mirete et al., 2020). Competency is defined as the ability to select and use knowledge, skills, and attitudes to respond successfully to a given situation (Garcia-Sanz \& Morillas, 2011). It is also defined as cognitive, affective, socio-emotional, and physical capacities in an integrated manner that allows students to act effectively (Perrenoud, 2004). ElSayary (2014) identified the competencies needed for teachers to teach STEM subjects such as critical thinking, creativity and innovation, connections, collaboration, self-direction, communication, and using technology as a tool. Interactive technology tools were introduced to

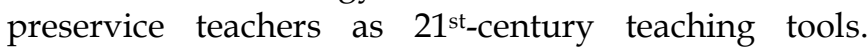
Preservice teachers may have access to various technologies, but it does not mean that they utilize them efficiently. They need supportive teacher education programs, professional development, and curricular alignment in order to utilize technologies efficiently (Hirsh \& Baronak, 2020). This notion was evident in early childhood classrooms where children were given tablets or iPads, which may or may not have been relevant to curriculum outcomes (Hirsh \& Baronak, 2020)

Interactive technology is the advancement of old technology with new modifications and additions that enhance an individual's life. Examples of interactive technology that enhanced students' learning are video streaming, simulations, learning games, augmented and virtual reality, and adaptive learning platforms (Soroka, 2018). The interactive technology fluency can empower teachers and students to build transferrable skills such as computational thinking, creativity and innovation, critical thinking, self-direction, collaboration, and communication. On the other hand, Bowen et al. (2017) mentioned that the intensive use of digital connectivity can cause a sense of isolation due to the non-presence of human interactions. Avoiding this sense of isolation can be achieved when students use technology independently to research, criticize, collaborate, solve problems, and apply what they have learned in new situations. Levy (2007) found that students who decided 
to drop out from e-learning courses had significantly lower satisfaction with e-learning than their student counterparts who also took part in on-campus courses. The development of technology tools improves people's lives, giving them easy access to information, and solving complex problems when utilized properly (Hirsh \& Baronak, 2020). Interactive technology use can lead to interactive learning where students assimilate information related to the real world. It is an enhanced social process where students lead their learning journey (Abykanova et al., 2016). The interactive learning caused by using interactive technology helps establish a friendly environment among learners and connecting to each other (Rybakova et al., 2021; Stupina, 2009). Learners will be creative and innovative when they are aware of themselves as learners who can use the information, act as research scientists, solve complex problems and empathize with individual needs in order to create new products that meet their needs (Abykanova et al., 2016). Previous researchers have stated that teachers and students should be involved in the analysis, design, development, and evaluation process when using interactive technologies as it leads learners to acquire integrated competencies while working on interdisciplinary technology-enhanced learning (Daniela et al., 2018; Scanlon et al., 2019).

Furthermore, students usually develop their understanding of the world when a potential change to their perspectives and frame of reference occurs (Mezirow, 2009). Due to the pandemic, online and blended learning approaches took place in schools and universities. Accordingly, students were situated in an uncomfortable situation that led them to question how they think and learn. Technology is considered to be a solution for education and became the main tool of communication and learning during the peak of the pandemic when many schools around the world moved to online learning. However, not all teachers were qualified to teach online using technology, and many gaps occurred.

This research aims to investigate the use of interactive technology in developing preservice teachers' STEAM competencies. In addition, this research will help recognize the guiding principles on how to move the field toward effective integration of interactive technology in the teacher training program. The following questions guided the study:

To what extent are preservice teachers trained to teach an integrated STEAM curriculum using interactive technology?

1. What is the impact of using interactive technology on developing preservice teachers' STEAM competencies?

2. What are the preservice teachers' perceptions about designing an integrated STEAM curriculum using interactive technology?

\section{Context of the Study}

Educational reform is one of the main goals of the UAE's 2030 agenda, where the integration of technology into education is at the forefront of the planned reformation. The UAE National Innovation Strategy (NIS) framework places innovation in technology as the primary role in shaping the future in order to ensure a better education and quality of life for UAE citizens and residents (UAE Government, 2015). Accordingly, NIS fosters innovation and technology in education through introducing creative teaching methods and strategies, especially in designing and developing innovative

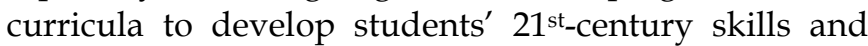
knowledge in the STEAM fields. A wide range of innovative technology initiatives have been introduced in the UAE, such as: Government and smart city initiatives; the Mohammed Bin Rashed Smart Learning Program (MBRSLP); the Emirates Foundation "Think Science" program; and the Abu Dhabi Center for Technical and Vocational Education and Training (ACTVET) launched the "Emirates Skills" program (Meda \& ElSayary, 2021).

The study was conducted in a federal university in the UAE that opened in 1998. It was a female university for Emirati women for the first ten years. In 2008, around 200 young men enrolled there. The university has two campuses in the country (Abu Dhabi and Dubai), with segregation of female and male students on each campus. The study included students from the early childhood education program at this university. Students in this program take educational courses, practicum courses, electives, and STEM courses, where each course is covered in one full semester. The sample of the study included preservice teachers who are enrolled in the STEM and practicum courses. Accordingly, the criteria set for the sample selection included preservice teachers who enrolled in semesters 3-7, in practicum courses, and in STEM courses.

In response to the pandemic, all schools and universities in the UAE shifted to distance learning. Accordingly, educators adjusted their plans to suit the new situation. In preparation for the distance learning, educators were encouraged to attend various professional development workshops, seminars, and short courses to learn how to design an interactive learning environment and ensure students' engagement in online learning. The researchers of this study are three faculty instructors. The first instructor specializes in STEM education and is a Certified Apple Teacher and Certified Online Instructor. The second instructor specializes in educational technology and mathematics education. The third instructor specializes in educational leadership, curriculum and instruction. The first two instructors taught the STEM courses from where the sample was selected. The third instructor introduced, explained and distributed the survey for the study to the participants. The courses' syllabi were taught to all 
Table 1. The form of the research pattern in quasi-experiment

\begin{tabular}{lccccc}
\hline Faculty & Group & Pretest & Application & Posttest & Focus group \\
\hline Instructor 1 & Control & O1 & Regular classes not including interactive technology & O3 & - \\
Instructor 2 & Experimental & O2 & Interactive technology application & O4 & 18 preservice teachers \\
\hline
\end{tabular}

students without any modifications. However, the delivery mode, including the way of teaching and the use of technology, differed between the two groups. The interactive technology applications were used in the experimental group while the control group received regular classes that did not include interactive technology applications.

\section{METHODOLOGY}

An explanatory sequential mixed-method design was used in this study to collect quantitative data, followed by qualitative data at the end of the spring semester. The quantitative data was collected using a quasi-experiment (pretest-posttest control group) and then qualitative data was collected using focus group discussion. The mixedmethod approach was used in this study with quantitative and qualitative data collection to avoid the bias of relying on one method (Johnson \& Christensen, 2014). The quantitative data was used to understand the impact and the qualitative data is used to understand the phenomenon in more depth. Table 1 shows form of the research pattern for experimental and control groups.

The treatment used in this study is the use of interactive technology applications, where the experimental group participants used multimedia applications, augmented reality apps, virtual reality trips, iCloud (pages, keynote, and numbers), iMovie, miro.com, Java, Python, Genially, Canva, Doodly, Google Classroom, EasyClass, Jamboard, and PowToon. The interactive technology tools were used to plan and design three integrated STEM themes and five learning centers for early childhood learners as part of the course work. On the other hand, the control group received regular classes that do not include interactive technology to plan and design five integrated themes and five learning centers. Both groups later presented end-ofsemester projects. Qualitative data was collected from 18 participants in the experimental group. The qualitative data collection aimed to gather in-depth information from the preservice teachers about their perceptions of using interactive technology applications.

\section{Participants}

The intended sample size was 110 preservice teachers studying at a federal university in the UAE. The criteria set for the participants were defined that they should be (i) enrolled in semesters 3-7, (ii) registered in Practicum I, II, or III courses, (iii) attending math, science, technology, and integrated curriculum courses, and (iv) willing to participate in the study. The preservice teachers attended the integrated STEM courses and applied what they learned in their practicum courses. In the practicum courses, preservice teachers were placed in private and governmental schools with different curricula: American, British, UAE's Ministry of Education (MOE), and International Baccalaureate (IB) curriculum.

The participants were all preservice teachers in the early childhood education program in a federal university. The sample were selected using a random cluster sample $(n=80)$. Then, the participants who didn't meet the criteria set were excluded from the study. The sample is distributed into two clusters (sections) the control group $\left(n_{c}=35\right)$ as one section and experimental group $\left(\mathrm{n}_{\mathrm{e}}=45\right)$ as another section. As stated by Johnson and Christensen (2014), the random cluster sample could be a school, class, section, or church. Accordingly, two sections were selected randomly out of four sections to represent the control and experimental groups. The participants were $100 \%$ females between the age of 18-35 years old, with the following percentages: 14 participants (17.5\%) were below 20; 60 participants $(75 \%)$ were between $21-25 ; 4$ participants (5\%) were between 26-30; and 2 participants (2.5\%) were between 31-35. Participants were enrolled in the semesters 3-7 with the following distribution: 5 participants $(6.3 \%)$ were in semester $3 ; 23$ participants $(28.7 \%)$ were in semester $4 ; 15$ participants $(18.8 \%)$ were in semester $5 ; 21$ participants $(26.3 \%)$ were in semester 6 ; and 16 participants $(20 \%)$ were in semester 7. A random sample of 18 preservice teachers were selected from the experimental group and disbursed into three focus groups. A fair explanation of the study's purpose and procedures was given to participants before conducting the study, and a consent form was sent for their signature. Participants had the choice of whether or not to participate in the study, and all instruments were anonymous.

\section{Instruments}

The preservice teachers' survey was used to conduct a quasi-experiment "pretest-posttest control group" to investigate the impact of using interactive technology in preparing them with the STEAM competencies. The dependent variables were defined as critical thinking, collaboration, communication, creativity and innovation, self-direction, connection, and interactive technology tools. The survey consisted of two main sections: demographic information and competencies. The first section concerning demographic information asked preservice teachers about the semester, age range, and the practicum courses they were enrolled in. The second section of the survey was adapted from ElSayary (2014) to include seven sub-sections: critical thinking (6 
items), collaboration (6 items), communication (5 items), creativity and innovation (5 items), self-direction (5 items), connection (5 items), and use of interactive technology (7 items). The total number of items in the second section is 39 items. The scale used in the survey was as follows: 1-almost never, 2-a few times of the semester, 3 is1-3 times per month, 4 is 1-3 times per week, and 5-almost daily. The survey was sent to two educational specialists to check the tool using qualitative content validity. They were asked to give feedback on the appropriateness of the items selected to fulfill the study's main purpose. The feedback received from the experts was to translate the survey items into the Arabic language to ensure students' understanding using their native language. Therefore, the survey was translated, and no further changes were made to the survey. The survey was sent to the same educational experts as they are bilingual to check the content validity and no further changes were required. The internal consistency of Cronbach's alpha was measured for the reliability of the instrument. The survey was piloted with 25 students, and the reliability test was valued at the following: $\alpha=0.897$ for critical thinking, $\alpha=0.929$ for collaboration, $\mathrm{a}=0.899$ for communication, $\mathrm{a}=0.932$ for creativity and innovation, $a=0.913$ for self-direction, $a=0.928$ for connection, and $\alpha=0.936$ for interactive technology use. The reliability test for the whole survey was valued at $0.979, \alpha>0.9$, considered suitable for the study.

The focus group discussion addressed the second question of the study. At the end of the course, three focus groups were conducted with selected students using open-ended reflective questions in order to narrow the lens and understand preservice teachers' perceptions. Each focus group included six students, to form 18 students in total in order to understand the phenomena from different perspectives of students. Johnson and Christensen (2014) stated that the focus group aims to understand the group's perceptions and impressions of products or programs. The focus group discussions were conducted online using Zoom (an online meeting application) with an average time of forty minutes each. The questions used were reflective openended questions suggested by Schon's (1987) reflection on learning (8 open-ended questions). The questions were sent to two educational experts to determine the face validity and clarity. The experts suggested merging two questions that led to the same answer (How did you engage in this course? And, in your opinion, what was the most creative part of your learning, and why do you think that is?) to be (How did you engage in this course? And what was the most creative part of your learning). They advised deleting the last two questions as these were considered to be repetitious of other questions. The total number of questions after addressing the experts' recommendations were six open-ended questions. The questions were listed as follows:

1. What is your background in using technology?
Table 2. Questionnaire score range of the means (Handal et al., 2013)

\begin{tabular}{lc}
\hline Score range & Description \\
\hline $1.0 \leq x<1.5$ & Very low \\
$1.5 \leq x<2.0$ & Low \\
$2.0 \leq x<2.5$ & Moderately low \\
$2.5 \leq x<3.0$ & Slightly below average \\
3.0 & Average \\
$3.0<x<3.5$ & Slightly above average \\
$3.5<x<4.0$ & Moderately high \\
$4.0<x \leq 4.5$ & High \\
$4.5<x \leq 5.0$ & Very high \\
\hline
\end{tabular}

2. What is the most important thing you learned in this course?

3. What do you want to learn more about, and why?

4. Do you think using interactive technology apps improves your performance? Why?

5. How did you engage in this course? And what was the most creative part of your learning?

6. In your opinion, what were the challenges you faced? Suggest ways to improve.

\section{Procedure}

This study was designed using an explanatory sequential mixed-method design, in which quantitative data was collected first, then the qualitative data was collected at the end of the semester. The quantitative approach was used to address the first question (What is the impact of using interactive technology on developing preservice teachers STEAM competencies?), using a quasi-experiment (pretest-posttest control group design) conducted with preservice teachers. The qualitative approach (focus group discussion) was used to address question 2 (What are the preservice teachers' perceptions about designing an integrated STEAM curriculum using interactive technology?).

Participants received consent forms at the beginning of the semester, and a full explanation of the study's purpose. Participants received a web-survey link as a pretest in the first two weeks of the semester. The experimental group practiced the use of interactive technology tools within the course work during a full semester (16 weeks), while the control group received the normal course work. The web-survey link as a posttest was sent to both groups. The descriptive to present each group's mean, standard deviation, and inferential statistics were used to run a one-way multivariate analysis of variance MANOVA test in order to analyze the impact of using interactive technology tools on developing preservice teachers' STEAM competencies. Handal et al.'s (2013) questionnaire score range (presented in Table 2) were used to explain and describe the results.

The qualitative data collected was used in the focus group discussions conducted at the end of the semester. 
Table 3. Descriptive statistics in preservice teachers' responses for the pretest and posttest

\begin{tabular}{|c|c|c|c|c|c|c|c|}
\hline & & & & SD & Std error & 95\% confidence & terval for mean \\
\hline & & $\mathrm{n}$ & Viean & SD & sta. error & Lower bound & Upper bound \\
\hline Critical thinkin & Post_experimental & 45 & 3.92 & .730 & .108 & 3.71 & 4.14 \\
\hline & Post_control & 35 & 4.08 & .841 & .142 & 3.79 & 4.37 \\
\hline & Pre_control & 35 & 3.49 & .828 & .140 & 3.20 & 3.77 \\
\hline & Pre_experimental & 45 & 3.25 & 1.193 & .177 & 2.89 & 3.61 \\
\hline Collaboration & Post_experimental & 45 & 4.07 & .821 & .122 & 3.82 & 4.31 \\
\hline & Post_control & 35 & 3.85 & 1.013 & .171 & 3.50 & 4.20 \\
\hline & Pre_control & 35 & 3.40 & .920 & .155 & 3.08 & 3.72 \\
\hline & Pre_experimental & 45 & 3.21 & 1.145 & .170 & 2.87 & 3.56 \\
\hline Communicatior & Post_experimental & 45 & 4.11 & .733 & .109 & 3.89 & 4.33 \\
\hline & Post_control & 35 & 4.15 & .638 & .107 & 3.93 & 4.37 \\
\hline & Pre_control & 35 & 3.59 & .847 & .143 & 3.30 & 3.88 \\
\hline & Pre_experimental & 45 & 3.24 & 1.041 & .155 & 2.93 & 3.56 \\
\hline Creativity \& & Post_experimental & 45 & 4.06 & .930 & .138 & 3.78 & 4.34 \\
\hline innovation & Post_control & 35 & 3.97 & .945 & .159 & 3.64 & 4.29 \\
\hline & Pre_control & 35 & 3.56 & .901 & .152 & 3.25 & 3.87 \\
\hline & Pre_experimental & 45 & 3.14 & 1.068 & .159 & 2.82 & 3.46 \\
\hline Self-direction & Post_experimental & 45 & 4.03 & .947 & .141 & 3.74 & 4.31 \\
\hline & Post_control & 35 & 3.81 & .873 & .147 & 3.51 & 4.11 \\
\hline & Pre_control & 35 & 3.57 & .960 & .162 & 3.24 & 3.90 \\
\hline & Pre_experimental & 45 & 3.35 & 1.155 & .172 & 3.00 & 3.70 \\
\hline Connection & Post_experimental & 45 & 4.13 & .813 & .121 & 3.89 & 4.38 \\
\hline & Post_control & 35 & 3.90 & .884 & .149 & 3.60 & 4.21 \\
\hline & Pre_control & 35 & 3.56 & .790 & .133 & 3.29 & 3.83 \\
\hline & Pre_experimental & 45 & 3.26 & 1.298 & .193 & 2.87 & 3.65 \\
\hline Interactive & Post_experimental & 45 & 4.27 & .822 & .122 & 4.02 & 4.52 \\
\hline technology & Post_control & 35 & 4.24 & .950 & .160 & 3.92 & 4.57 \\
\hline & Pre_control & 35 & 3.86 & .868 & .146 & 3.56 & 4.16 \\
\hline & Pre_experimental & 45 & 3.55 & 1.351 & .201 & 3.14 & 3.96 \\
\hline
\end{tabular}

There were three focus group discussions with six preservice teachers in each group selected from the experimental group. The discussions were conducted through Zoom for 30-50 minutes each, with an average of 40 minutes. The participants' responses were interpreted to provide rich textual data clarification based on the questions presented during the focus group discussions. The main purpose was to let participants freely express themselves in providing reflection on their experiences. The open-ended questions used were based on Schon's (1987) reflection on learning. The results were analyzed and integrated with the quantitative results to avoid any bias that might occur in collecting one type of data.

\section{RESULTS}

\section{Equivalency and Adequacy of the Two Groups}

The descriptive statistics of the pretest-posttest experimental and control groups were calculated and are presented in Table 3. In critical thinking, the results show that the mean of the pretest control group $(M=3.49$, $S D=0.828)$ is slightly higher than the mean of the experimental group $(M=3.25, S D=1.19)$. In collaboration, the results show that the mean of the pretest control group $(M=3.40, S D=0.920)$ is slightly higher than the mean of the experimental group $(M=3.21, S D=1.14)$. In communication, the results show that the mean of the pretest control group $(M=3.59, S D=0.847)$ is slightly higher than the mean of the experimental group $(M=3.24, S D=1.04)$. In creativity and innovation, the results show that the mean of the pretest control group $(M=3.56, S D=0.901)$ is slightly higher than the mean of the experimental group $(M=3.14, S D=1.06)$. In selfdirection, the results show that the mean of the pretest control group $(M=3.57, S D=0.96)$ is slightly higher than the mean of the experimental group $(M=3.35, S D=1.15)$. In connection, the results show that the mean of the pretest control group $(M=3.56, S D=0.79)$ is slightly higher than the mean of the experimental group $(M=3.26, S D=1.29)$. In interactive technology, the results show that the mean of the pretest control group $(M=3.86$, $S D=0.868)$ is slightly higher than the mean of the experimental group $(M=3.55, S D=1.35)$.

The equivalency and adequacy between the control and experimental groups were measured by conducting a one-way multivariate analysis of variance, before running the quasi-experiment. The results showed no 
Table 4. The MANOVA test to show the differences between the experimental and control groups

\begin{tabular}{|c|c|c|c|c|c|c|c|}
\hline \multicolumn{8}{|c|}{ Multivariate tests ${ }^{\mathrm{a}}$} \\
\hline Effect & & Value & $\mathrm{F}$ & Hypothesis df. & Error df. & Sig. & $\eta_{p^{2}}$ \\
\hline \multirow[t]{4}{*}{ Intercept } & Pillai's trace & .956 & $463.322^{b}$ & 7.000 & 150.000 & .000 & .956 \\
\hline & Wilks' lambda & .044 & $463.322^{b}$ & 7.000 & 150.000 & .000 & .956 \\
\hline & Hotelling's trace & 21.622 & $463.322^{b}$ & 7.000 & 150.000 & .000 & .956 \\
\hline & Roy's largest root & 21.622 & $463.322^{b}$ & 7.000 & 150.000 & .000 & .956 \\
\hline \multirow[t]{4}{*}{ Groups } & Pillai's trace & .292 & 2.345 & 21.000 & 456.000 & .001 & .097 \\
\hline & Wilks' lambda & .725 & 2.434 & 21.000 & 431.269 & .000 & .102 \\
\hline & Hotelling's trace & .356 & 2.518 & 21.000 & 446.000 & .000 & .106 \\
\hline & Roy's largest root & .274 & $5.945^{c}$ & 7.000 & 152.000 & .000 & .215 \\
\hline
\end{tabular}

Note. aDesign: Intercept+Groups; ${ }^{b}$ Exact statistic; ${ }^{c}$ The statistic is an upper bound on F that yields a lower bound on the significance level

Table 5. MANOVA test result of between-subjects effects

\begin{tabular}{|c|c|c|c|c|c|c|}
\hline Source & Dependent variable & Type III sum of squares & df. & Mean square & $\mathrm{F}$ & Sig. \\
\hline \multirow[t]{7}{*}{ Intercept } & Critical thinking & 2144.936 & 1 & 2144.936 & 2506.021 & .000 \\
\hline & Collaboration & 2084.174 & 1 & 2084.174 & 2151.018 & .000 \\
\hline & Communication & 2247.022 & 1 & 2247.022 & 3195.325 & .000 \\
\hline & Creativity & 2141.769 & 1 & 2141.769 & 2282.177 & .000 \\
\hline & Self-direction & 2150.629 & 1 & 2150.629 & 2156.171 & .000 \\
\hline & Connection & 2179.176 & 1 & 2179.176 & 2249.962 & .000 \\
\hline & Interactive technology & 2502.032 & 1 & 2502.032 & 2343.626 & .000 \\
\hline \multirow[t]{7}{*}{ Groups } & Critical thinking & $17.929 a$ & 3 & 5.976 & 6.982 & .000 \\
\hline & Collaboration & $19.916^{\mathrm{b}}$ & 3 & 6.639 & 6.851 & .000 \\
\hline & Communication & $23.701^{c}$ & 3 & 7.900 & 11.235 & .000 \\
\hline & Creativity & $22.957^{d}$ & 3 & 7.652 & 8.154 & .000 \\
\hline & Self-direction & $11.277^{\mathrm{e}}$ & 3 & 3.759 & 3.769 & .012 \\
\hline & Connection & $19.179 \mathrm{f}$ & 3 & 6.393 & 6.601 & .000 \\
\hline & Interactive technology & $14.962 \mathrm{~g}$ & 3 & 4.987 & 4.671 & .004 \\
\hline \multirow[t]{7}{*}{ Error } & Critical thinking & 133.522 & 156 & .856 & & \\
\hline & Collaboration & 151.152 & 156 & .969 & & \\
\hline & Communication & 109.703 & 156 & .703 & & \\
\hline & Creativity & 146.402 & 156 & .938 & & \\
\hline & Self-direction & 155.599 & 156 & .997 & & \\
\hline & Connection & 151.092 & 156 & .969 & & \\
\hline & Interactive technology & 166.544 & 156 & 1.068 & & \\
\hline \multirow[t]{7}{*}{ Total } & Critical thinking & 2316.028 & 160 & & & \\
\hline & Collaboration & 2289.306 & 160 & & & \\
\hline & Communication & 2401.440 & 160 & & & \\
\hline & Creativity & 2333.200 & 160 & & & \\
\hline & Self-direction & 2351.360 & 160 & & & \\
\hline & Connection & 2381.440 & 160 & & & \\
\hline & Interactive technology & 2711.878 & 160 & & & \\
\hline
\end{tabular}

Note. aR squared=.118 (Adjusted R squared=.101); bR squared=.116 (Adjusted R squared=.099); $c \mathrm{R}$ squared=.178 (Adjusted R squared=.162); $\mathrm{d}$ squared=.136 (Adjusted $\mathrm{R}$ squared=.119); $\mathrm{R}$ squared=.068 (Adjusted R squared=.050); $\mathrm{f}$ squared=.113 (Adjusted $\mathrm{R}$ squared $=.096) ; \mathrm{g}$ R squared $=.082$ (Adjusted $\mathrm{R}$ squared $=.065$ )

significant difference between the pretest of the experimental and control groups, as follows: critical thinking $(p=0.67), \quad$ collaboration $\quad(p=0.83)$, communication $(\mathrm{p}=0.83)$, creativity and innovation $(p=0.21)$, self-direction $(p=0.22)$, connection $(p=0.22)$, and interactive technology use $(p=0.23)$.

\section{The Impact of Interactive Technology Use on Preservice Teachers' STEAM Competencies}

Following the descriptive statistics analysis and the equivalency and adequacy test, the two groups' means were compared using the multivariate analysis of variance (shown in Table 4). There was a statistically significant difference between the control and experimental groups, $\mathrm{F}(21,431.2)=2.43$, $\mathrm{p}<.05$; Wilk's $\Lambda=.725, \eta_{\mathrm{p}}{ }^{2}=0.102$.

The MANOVA test results of between-subjects' effects for the dependent variables are shown in Table 5. The results of the pretest-posttest control and experimental groups show significant differences in all categories, as per the following: critical thinking skills reveal significant difference $(F(3,156)=6.982, p<0.001$, $\left.\eta^{2}=0.12\right)$; collaboration skills reveal significant difference 
$\left(\mathrm{F}(3,156)=6.851, \mathrm{p}<0.001, \mathrm{\eta}^{2}=0.12\right)$; communication skills reveal significant difference $(F(3,156)=11.235, p<0.001$, $\left.\eta^{2}=0.18\right)$; creativity and innovation skills reveal significant difference $\left(\mathrm{F}(3,156)=8.154, \mathrm{p}<0.001, \mathrm{\eta}^{2}=0.14\right)$; self-direction skills reveal significant difference $(\mathrm{F}(3$, 156)=3.769, $\left.\mathrm{p}<0.001, \mathrm{\eta}^{2}=0.07\right)$; connection skills reveal significant difference $(F(3,156)=6.601, \quad p<0.001$, $\left.\eta^{2}=0.113\right)$; the interactive technology use skills reveal significant difference $(\mathrm{F}(3,156)=4.671, \mathrm{p}<0.001$, $\left.\eta^{2}=0.082\right)$.

According to Cohen's (1988) guidelines, the differences between critical thinking, collaboration, selfdirection, connection, and interactive technology have a medium effect size, with $0.06>\eta_{\mathrm{p}}{ }^{2}<0.14$ and a high power level. However, the differences between communication, creativity and innovation skills have a large effect size, with $\eta_{\mathrm{p}}^{2}>0.14$ and a high power level. As a result, the null hypothesis was rejected, and it was determined that the slight difference found between the means of the pretest control and pretest experimental group did not affect the results.

In addition, a one-way analysis of variance was conducted to compare between the pretest and posttest experimental and control groups. The results showed a significant difference between the pretest and posttest of the experimental group $(\mathrm{p}<0.05)$ and a significant difference between the posttest experimental and control groups, with $(\mathrm{p}<0.05)$ regarding the STEAM competencies.

\section{Focus Group Discussion Analyses}

The focus group discussion meetings were held online using Zoom conference. The responses stated below were categorized based on the questions presented in the focus group discussions.

\section{Q1: What is your background in using technology?}

Most preservice teachers mentioned that they had appropriate skills in using technology. This is because they used technology in high school prior to joining the university. However, some students stated that they have anxiety using technology, especially when they have a project or task requiring new applications. Some of the responses are provided below:

Student 1: "I use technology in almost everything in my life. I use social media to communicate with friends and family. Also, we receive important news related to our universities on them. I also use it when we have assignments, projects, or tasks to work on."

Student 2: "I feel anxious when using a new application to finish my project. I took time to understand how to use the application. I always have anxiety trying new applications."
Student 3: “Using technology is enjoyable for me. I feel like I couldn't handle my tasks without using technology. I depend on it in all my work and use it as well for entertainment."

\section{Q2: What is the most important thing you learned in this course?}

Preservice teachers shared different things they learned. Some of the preservice teachers highlighted that they learned new teaching and learning strategies, while others mentioned that they never thought of using interactive technology in this way. Some of the responses were as follows:

Student 1: "I have learned how to use technology in creating integrated STEAM themes for early years. It is wonderful in making learning more interesting for students."

Student 2: "I learned new applications that can be utilized in teaching and learning without feeling the challenges of and stress of teaching online."

Student 3: "I learned how to raise early years' students to a higher-order thinking and develop their creativity using different applications of augmented and virtual reality."

Student 4: "I understood what, how and when to use each application we learned. Before that, I was confused about the different applications and how and when to use them. For example, I can now create animated videos using Doodly or Canva, interactive presentations using Genially, interactive journals using iCloud pages, creating an interactive story using PowToon, etc."

Student 5: "I enjoyed creating a virtual classroom and how to organize tasks and lessons in this classroom. I feel like I have rich knowledge about how to use technology interactively."

\section{Q3: What do you want to learn more about, and why?}

All preservice teachers took some time to think about what they wanted to learn more about. Most of their responses were about teaching online, as shared below:

Student 1: "I want to learn how to engage early years' students to do group activities in an online setting. I want to be prepared for teaching online in case any emergency crisis occurs."

Student 2: "I want to learn how to assess early years' students' learning in an online environment. We use mainly classroom observation for early years' assessment to check their understandings, but I wonder how I can do the observation online." 
Student 3: "Managing students in early years is challenging in face-to-face learning. In case we had to teach them online, how can we manage their behavior to engage them in learning and ensure that everyone is on task?"

Student 4: "I need to know how to engage students and convince parents to collaborate with their kids during the online learning."

\section{Q4: Do you think using interactive technology apps improves your performance? Why?}

All preservice teachers agreed that they enjoyed their learning and felt that they improved after using interactive technology. Some of the responses are shared below:

Student 1: "I have enjoyed learning using interactive applications and felt the sense of achievement after every task I do and submit it. This gave me the motivation to learn more and try new interactive applications."

Student 2: "I felt more creative in the way I used technology. I liked how to create interactive tasks for early years and guide them to be active learners."

Student 3: "I feel that I am almost ready to teach either online, face-to-face or in a blended learning environment."

Student 4: "I feel my performance has been improved because using interactive applications allowed me to produce creative learning tasks. I received very positive feedback from my instructor. This gave me the confidence to use them again and try them in a different context."

\section{Q5: How did you engage in this course? And what was the most creative part of your learning?}

Preservice teachers were excited to share their experiences in explaining the tasks they created collaboratively. In addition, they reflected and responded to each other about time they spent completing their tasks together. Some of the responses are shared below:

Student 1: "We have created an interactive story for early years using different applications such as iCloud Pages, Canva, and PowToon. We loved the idea of creating the story according to the theme we teach. Sometimes we can't find a story that is related to the theme we teach. However, we created it in the way we want and aligned it to the learning outcomes."
Student 2: "I liked how we created a virtual classroom and combined all the tasks in one place, where students and their parents can receive materials easily without getting distracted by many emails and paper printouts."

Student 3: "We have created interactive journals as a weekly reflection in our course. It was a nice experience as we don't only reflect in writing, we also provided videos, photos, and sometimes adding games as examples to support our opinions."

Student 4: "I liked almost everything, and all tasks we created were really creative. We felt as if we are not preservice teachers but designers who can design learning, rather than teaching."

\section{Q6: In your opinion, what were the challenges you faced? Suggest ways to improve.}

Preservice teachers shared some challenges they faced. Some of their responses are as follows:

Student 1: "I felt challenged at the beginning of the semester when we used the applications for the first time. It took me some time for us to understand how to use them. Our instructor has recorded videos for us about how to use each of these applications."

Student 2: "We had many tasks and felt overwhelmed to finish them all on time. I recommend reducing the amount of reflection so we can focus more on using these applications and try to work in depth on various ways to use them."

Student 3: "I believe we need to have two weeks at the beginning of the semester to learn about different applications and their uses before starting our tasks. This will reduce the time wasted on understanding how to use new applications in learning tasks."

Student 4: "I recommend having other courses the same way we were taught this semester. The experience we had was wonderful, and we felt that we need more time to learn more applications and know how to apply them."

\section{DISCUSSION}

\section{The Impact of Using Interactive Technology}

The results showed that preservice teachers had developed their STEAM competencies using interactive technology. The same result occurred in a previous study by Chai et al (2020), who stated that technology in planning lessons was a reliable pedagogical approach 
that enhances teachers' competencies. The creativity and innovation competency showed a significant difference in the way preservice teachers used interactive technology. This was supported during the focus group discussion, where preservice teachers shared many examples about how they interactively used the technology to design interactive STEM lessons for early years. This was considered to be the transformative domain that was discussed by Capone and Lepore (2021). It was evident through the students' responses, where they felt they were designers of the learning environment. Aykanova et al. (2016) emphasized that learners become creative and innovative when they use the information, act as researchers, solve complex problems, and empathize with the users' needs in order to create innovative products that meet their needs. These are the sub-skills that were developed within the TPCK domains.

Also, the preservice teachers' communication and collaboration skills improved, and the results showed significant differences. During their discussions, they mentioned that most of their tasks were collaborative work, and the virtual communication between their peers and their instructor facilitated their learning. In addition, one of the comments mentioned that the recorded explanation videos created by the instructor helped them understand how to use the new interactive applications in the learning task and review the videos whenever needed.

On the contrary, Bowen et al. (2017) mentioned that the intensive use of digital connectivity can cause a sense of isolation. However, the results aligned with previous studies that emphasized that the interactive learning environment caused by interactive technology usage helped in establishing a friendly environment among learners (El Sayary, 2014).

The critical thinking skills also improved, as the survey results showed significant differences. This was evident as well through the focus group discussions, where preservice teachers mentioned that they were responsible for submitting weekly reflections in interactive journals. Students felt that they understood the various ways of using interactive technology, especially after doing their reflective statements using their interactive journals. They felt free to choose the method they were interested in to create their journals. This allowed them to do their work comfortably and creatively while meeting their learning needs. This result is compatible with Hirsh and Baronak (2020) and Rybakova et al. (2021), who emphasized that learners empathize, research, analyze, and design new products that meet their learners' needs.

Regarding self-direction skills, the results showed significant differences, which was also evident in the discussion. The preservice teachers were excited to share their experiences about how they created their tasks using interactive applications. They mentioned many things, such as creating an interactive story for a specific theme they had created. They felt confident to create a story rather than find one that was not aligned with the theme. This result was confirmed by Abykanova et al. (2016), who highlighted that learners who used interactive technology were aware of themselves as learners and were able to direct their learning journey in an enhanced social process.

The results showed a significant difference as well in the areas of connection and the use of interactive technology. This was evident in the focus group discussion, where most of them shared many ideas about how they used the interactive applications to create their integrated themes for early years. They also shared how they used interactive applications in completing their tasks. Rybakova et al. (2021) emphasized the important use of interdisciplinary technology-enhanced learning that led learners to develop their STEAM competencies as they are able to connect between different concepts and subjects.

\section{Preservice Teachers' Perceptions About Designing Integrated STEAM Curriculum Using Interactive Technology}

Preservice teachers had very positive experiences of using interactive technology to design the STEAM curriculum. They shared that at the beginning of the course, they had anxiety about using the technology. However, after completing the course, they felt more confident in using interactive technology. This was also evident in the results of the quantitative analysis of the data collected from the survey. This was confirmed by Hirsh and Baronak (2020), who stated that interactive technology led to an interactive learning environment where the stress and anxiety of using technology were reduced.

Levy (2007) highlighted that students' lack of interest in and dissatisfaction with online learning contributed to their dropout from e-learning courses. However, this was not noticed in the results of the current study, as students understood the importance of interactive technology in their learning through the STEAM tasks they designed. Preservice teachers mentioned that they did not feel that they were planning STEM tasks; they had the sense of designing creative tasks aligned to the learning outcomes. They shared that they created virtual classrooms with specific themes and provided different materials created in this classroom, such as animated videos, interactive stories, interactive presentations, and games. In addition, they explained different ways of using the interactive technology, such as creating interactive journals to use for their weekly reflection. They highlighted the benefits of the interactive journals, where they felt they could reflect in the way that suited them. As a result, some students reflected by using photos, gallery photos, recorded videos, and games. The 
interactive journals presented preservice teachers' reflections that proved their satisfaction in meeting their learning needs and styles. Many researchers emphasized the importance of using interactive technology such as video streaming, simulations, learning games, and augmented and virtual reality as tools that empower teachers and learners to acquire transferrable skills such as computational thinking, creativity and innovation, critical thinking, self-direction, collaboration, and communication (Soroka, 2018).

Preservice teachers shared many ideas about what they wanted to learn more about, the challenges they faced, and they gave overall suggestions. They mentioned that they want to learn more about managing early years' students in an online setting. They also wanted to learn more about strategies to assess early years' students during online learning. Preservice teachers wanted to learn more about ideas to engage parents and collaborate with them, for the sake of their students. The same challenge was highlighted in a previous study where early childhood classrooms received tablets or iPads that may or may not be relevant to curriculum outcomes and were not appropriately utilized to meet the learners' needs (Hirsh \& Baronak, 2020).

The biggest challenge they faced was the time needed to accomplish their learning tasks. They felt overwhelmed with their tasks and the time needed to understand how to use the interactive applications. Preservice teachers suggested having other courses to learn using interactive technology and having two weeks at the beginning of the semester to learn about the interactive applications before starting their learning tasks. Researchers in previous studies have emphasized the need for revamping teacher education programs to focus on the use of interactive technology and to enhance in-service teachers' TPACK skills by providing a range of professional development programs (Abykanova et al., 2016; Daniela et al., 2018; Hirsh \& Baronak, 2020; Rybakova et al., 2021; Scanlon et al., 2019).

\section{CONCLUSIONS AND RECOMMENDATIONS}

The purpose of this study was to investigate to what extent preservice teachers are prepared to teach an integrated STEAM curriculum using interactive technology. The study results revealed that the preservice teachers developed their STEAM teaching skills using interactive technology in an early childhood education program. There was a significant difference in the way they used the technology before and after taking the interactive technology training. The transformative domain of integrating technology, pedagogy and content knowledge discussed by Capone and Lepore (2021) was followed in this study with the use of interactive technology applications. The participants faced some challenges related to time management in understanding interactive technology in creating their tasks. They also found inconsistency in the way other courses were taught. It is highly recommended to revamp the undergraduate courses to integrate interactive technology in teaching and learning in order to avoid students' dropouts, as stated by Levy (2007). Education study programs should give more weight to technology use, especially in the wake of the COVID-19 quarantine, when face-to-face teaching and learning was suddenly shifted online. It was also recommended to create professional development training for instructors who teach preservice teachers. Instructors need to follow the transformative model of the technological pedagogical content knowledge in order to efficiently guide preservice teachers and avoid students losing interest and dropping out.

Further studies need to be conducted to focus on the instructors' perspectives about interactive technology in teaching and learning. In addition, other studies about the use of the design thinking process and the reflective process while using interactive technology should be considered. Preservice teachers' journals analysis is another tool that would add to the study in order to understand the level of reflection the participants reached after meeting their learning needs and styles.

Author contributions: All authors have sufficiently contributed to the study, and agreed with the results and conclusions.

Funding: No funding source is reported for this study.

Declaration of interest: No conflict of interest is declared by authors.

\section{REFERENCES}

Abykanova, B. Nugumanova, S. Yelezhanova, S. Kabylkhamit, Z., \& Sabirova, Z. (2016). The use of interactive learning technology in institutions of higher learning. International Journal of Environmental \& Science Education, 11(18), 1252812539.

Bowen, G., Gordon, N., \& Chojnacki, M. (2017). Advocacy through social media: Exploring student engagement in addressing social issues. Journal of Higher Education Outreach and Engagement, 21(3), 530. https:/ / eric.ed.gov/?id=EJ1156183

Capone, R., \& Leopre, M. (2021). From distance learning to integrated digital learning: A fuzzy cognitive analysis focused on engagement, motivation, and participation during COVID-19 pandemic. Technology, Knowledge and Learning. https://doi.org/10.1007/s10758-021-09571-w

Chai, C. S., Rahmawati, Y., \& Jong, M. S. (2020). Indonesian science, mathematics, and engineering preservice teachers' experiences in STEM-TPACK design-based learning. Sustainability, 12(21), 9050. https:/ / doi.org/10.3390/su12219050 
Daniela, L. Visvizi, A., Gutiérrez-Braojos, C., \& Lytras, M. (2018). Sustainable higher education and technology-enhanced learning (TEL). Sustainability, 10(1), 1-22. https:/ / doi.org/10.3390/su10113883

Drake, S. M., \& Reid, J. (2017). Interdisciplinary assessment in the 21st century. Academic Exchange Quarterly, 21(1), 1096-1453. http://www. rapidintellect.com/AE/ec5771v14.pdf

El Sayary, A. M. A. (2014). The effectiveness of problembased learning strategy in STEM education for enhancing students' 21st century skills. The British University in Dubai (BUID) Digital Repository.

García-Sanz, M. P., \& Morillas, L. R. (2011). La planificación de evaluación de competencias en educación superior [Competency assessment planning in higher education]. Revista Electrónica Interuniversitaria de Formación del Profesorado [Interuniversity Electronic Journal of Teacher Training], 14(1), 113-124. http:/ / www.aufop.com/ aufop/uploaded_files/articulos/1302193022.pdf

Gess-Newsome, J. (1999). Pedagogical content knowledge: An introduction and orientation. In J. Gess-Newsome, \& N. G. Lederman (Eds.), Examining pedagogical content knowledge (pp. 3-17). Springer. https://doi.org/10.1007/0-306-472171_1

Handal, B., Campbell, C., Cavanagh, M., Petocz, P., \& Kelly, N. (2013). Technological pedagogical content knowledge of secondary mathematics teachers. Contemporary Issues in Technology and Teacher Education, 13(1), 22-40.

Hirsh, R. A., \& Baronak, K. (2020). Empowering early childhood pre-service teachers with tech fluency. Creative Education, 11, 2730-2748. https://doi.org/ $10.4236 /$ ce. 2020.1112200

Johnson, B., \& Christensen, L. (2014). Educational research: quantitative, qualitative, and mixed-method. SAGE.

Levy, Y. (2007). Comparing dropouts and persistence in e-learning courses. Computers $\mathcal{E}$ Education, 48, 185204. https:/ / doi:10.1016/j.compedu.2004.12.004

Meda, L., \& ElSayary, A. (2021). Establishing social, cognitive and teacher presences during emergency remote teaching: Reflections of certified online instructors in the United Arab Emirates. Contemporary Educational Technology, 13(4), ep318. https:/ / doi.org/10.30935/cedtech/11073

Mezirow, J. (2009). An overview on transformative learning. In K. Illeris (Ed.), Contemporary theories of learning: Learning theorists...in their own words (pp. 90-105). Routledge.

Mirete, A. B., Maquilon, J. J., Mirete, L., \& Rodriguez, R. A. (2020). Digital competence and university teachers' conceptions about teaching. A structural causal model. Sustainability, 12(12), 2842. https:/ / doi.org/10.3390/su12124842

Mohebi, L. (2018). Investigating perceptions of pre-service teachers and instructors about TPACK capabilities of pre-service teachers: An explanatory study among selected UAE universities [PhD thesis, The British University in Dubai (BUiD)]. https://doi.org/ 10.2139 /ssrn.3421436

Perronoud, P. (2004). Diez nuevas competencias a enseñar [Ten new skills to teach]. Magisterio Editorial.

Pierson, M. E. (2001). Technology integration practice as a function of pedagogical expertise. Journal of Research on Computing in Education, 33(4), 413-430. https:/ / doi.org/10.1080/08886504.2001.10782325

Rybakova, A., Shcheglova, A., Bogatov, D., \& Alieva, L. (2021). Using interactive technologies and distance learning in sustainable education. E3S Web of Conferences, 250(07003), 1-7. https://doi.org/10. 1051/e3sconf/202125007003

Scanlon, E., Anastopoulou, S., Conole, G., \& Twiner, A. (2019). Interdisciplinary working methods: Reflections based on technology-enhanced learning (TEL). Frontiers in Education, 4, 134. https://doi.org/10.3389/feduc.2019.00134

Schon, D. A. (1987). Educating the reflective practitioner. Jossey-Bass.

Schwab, K., \& Zahidi, S. (2020). The future of jobs report 2020. World Economic Forum. http:/ / www3.weforum.org/docs/WEF_Future_o f_Jobs_2020.pdf

Soroka, O. (2018) The concept of "interactive technology" in educational science and practice. Azerbaijan Journal of Educational Studies, 685(4), 5576. http:/ / doi.org/10.32906/AJES/683.2018.04.28

Stupina, S. B. (2009). Tekhnologii interaktionogo obucheniya $v$ vysshei shkole: Uchebno-metodicheskoe posobie [Interactive learning technology in college: A teaching guide]. Science, p. 52.

UAE Government. (2015). Science, technology and innovation policy in the United Arab Emirates. UAE Government.

UAE National Committee on SDGs. (2017). UAE and the 2030 agenda for sustainable development: Excellence in implementation. https://sustainabledevelopment. un.org/content/documents/20161UAE_SDGs_Re port_Full_English.pdf

UAE Vision 2021. (2009). Vision 2021: United in ambition and determination. Abu Dhabi: United Arab Emirates. http:/ / www.vision2021.ae

Yakman, G. (2010). STEAM: A framework for teaching across the disciplines. Virginia Polytechnic and State University. 